\title{
Performing the bio-urban in Bonnie Ora Sherk's The Farm and Mierle Laderman Ukeles's Flow City
}

Article

Accepted Version

Woynarski, L. (2020) Performing the bio-urban in Bonnie Ora Sherk's The Farm and Mierle Laderman Ukeles's Flow City. Performance Research, 25 (2). pp. 124-131. ISSN 1469-9990 doi: https://doi.org/10.1080/13528165.2020.1752585 Available at https://centaur.reading.ac.uk/90431/

It is advisable to refer to the publisher's version if you intend to cite from the work. See Guidance on citing.

To link to this article DOI: http://dx.doi.org/10.1080/13528165.2020.1752585

Publisher: Taylor \& Francis

All outputs in CentAUR are protected by Intellectual Property Rights law, including copyright law. Copyright and IPR is retained by the creators or other copyright holders. Terms and conditions for use of this material are defined in the End User Agreement.

www.reading.ac.uk/centaur

\section{CentAUR}


Central Archive at the University of Reading

Reading's research outputs online 


\section{Towards Radical Coexistence in the City: Performing the bio-urban in Bonnie Ora Sherk's The Farm and Mierle Laderman Ukeles's Flow City Lisa Woynarski}

1974. A busy highway interchange in San Francisco under US 101 where 16th Street and Potrero Street cross. Four diverse neighbourhoods surround it. Three creeks flow underneath. In the middle of this concrete jungle sits a seven-acre working farm in what was formerly an abandoned lot. A field of crops is growing in the shadow of a highway overpass. A theatre, a rehearsal space, a library, as well as farm staples like chickens, orchards and working fields. Artists live in residence, interacting with school children and local community members who come to visit, play and work. This is The Farm, an environmental performance project/community conceived by Bonnie Ora Sherk.

1983. The New York City (NYC) Sanitation Department. Artist Mierle Laderman Ukeles has a vision for the new 59th Street Marine Transfer Station in Manhattan: an installation and site-specific performance called Flow City. This is where 800 to 3,000 tonnes of waste will be processed each year. In Ukeles's design a visitor centre will sit amidst the waste. Visitors will enter through a passageway brimming with materials recycled from the NYC Sanitation Department. They will then proceed to cross a Glass Bridge where visitors can watch garbage trucks unloading their contents onto river barges on the Hudson River that will then deliver the garbage to Fresh Kills Landfill on Staten Island. Finally, they will come to the Media Flow Wall filled with screens that show camera footage of what is happening above and below the Hudson River as well as at the Fresh Kills Landfill, connecting them with the invisible and remote processes of their trash. Some aspects of Ukeles's Flow City were realized, while others remained imagined.

In the 1970s and 1980s, in America, two white, feminist performance artists were thinking about the interactions of their feminist politics and the way in which urban development was shaping city life in unequal and stratified ways. Rapid development of cities seemed to be happening with little thought for the ecological systems 
embedded in them or the differentiated people who lived and worked there. Both Sherk and Ukeles enacted alternative possibilities to urban living in their performance works. Responding and resisting the capitalist values that were governing city life, Sherk's The Farm and Ukeles's Flow City imagined radical ways of living in cities together. These performances modelled processes for re-imagined urban living, relevant to contemporary urban conditions and intersectional ecological thinking.

\section{In dark ecology}

In the time since these two works were made, there have been many signs that we are living in 'dark'[\{note\}]1 ecological times. Rising populism, unbridled neoliberal capitalism and deepening inequality coupled with drought, floods, fires, forced migration, murdered environmentalists and the ever-increasing effects of climate crisis. A 'dark' ecology is one that acknowledges the crisis situation of overlapping catastrophes we are currently facing, all of which result in ecological vulnerability (and therefore makes human life vulnerable). 'Dark' ecology confronts these realities, through artistic means like the Dark Mountain Project (a network of writers and artists) whose 'dark' ecology is resisting the grand narrative of progress and civilization as it has failed in the current climate of crisis. "We see that the world is entering an age of ecological collapse, material contraction and social and political unravelling, and we want our cultural responses to reflect this reality rather than denying it' (The Dark Mountain Project 2015). Art forms, such as theatre and performance, may provide respite to this grief or may reshape our sense of interdependence on the more-than-human world.

Timothy Morton describes dark ecology as a logic of future coexistence (2016:1). It subverts the pastoral undertones of work that romanticized and fetishized rural landscapes as 'pure' spaces of 'nature'. It is about ecological thinking that goes beyond the idea of 'green and pleasant', which is limiting, outdated and exclusionary, often with racial discriminatory undertones. 'Ecology as green also perpetuates the implications of binary nature-culture separation (simplistic for both sides of the human-nonhuman divide)' (Buell 2013: ix-x). In the following, I consider coexistence now-how we might rethink and reframe our coexistence with and in 
urban spaces and urban inhabitants (both human and more-than-human). What we might consider bleak—global urban growth and migration —may provide an opportunity to re-conceptualize how we understand urban 'nature' and city life. In this 'urban century' (Gaston 2010: 14), urban growth and sprawl, sacrificing green spaces for development, often for commercial use that is unattainable for the majority of local residents, is undeniably negative. However, in this so-called darkness is opportunity. By understanding the urban as an ecologically vibrant space, we can remake our relationship to the city. I introduce the neologism the biourban to indicate the way in which vibrant ecological relationships are present in city spaces. By considering two performance practices that reimagine how people could live and interact with the city, I argue that performance can foster a recognition of the ecological agency of the more-than-human, offering a theory for coexistence in 'dark' ecological times.

I theorize the way in which performance opens up the perceptual possibility of dissolving the urban/nature dualism in order to think of the city as an ecologically 'alive' space, or what I term bio-urban in Sherk's The Farm and Ukeles's work at the New York Sanitation Department. Both these examples are based in large American cities and therefore do not offer a global perspective. However, these performance projects are intersectional in that they invest and foreground the marginalized people, voices and more-than-human actants in their contexts and are therefore applicable to other cities and urban experiences. What I call intersectional ecologies acknowledges the agency of the more-than-human in social and political contexts and the way in which the slow violence of ecological destruction is intimately interconnected with other forms of violence (Nixon 2011). Drawing on these two performance works, I argue that an intersectional ecological perspective is a necessary addition to any ecological thinking.

\section{Bonnie Ora Sherk's The Farm (San Francisco 1974-80)}

The location of Sherk's farm, called Crossroads Community, was a derelict six-anda-half-acre cement site surrounded by a busy freeway interchange on San Francisco's then Army Street and empty warehouses. Funded by public money available for the creation of open spaces after the completed development of the 
motorway interchange, The Farm was a working farm that was also part social experiment and part community art project. Sherk eventually built up the site to include a garden, a farm, a park, a school without walls, an alternative art space, performance space, community centre, environmental education centre, a cafe, kitchen, library and more. Visitors, artists (including the San Francisco Mime Troupe), community members and local school groups ran and maintained the farm, learning to grow food and tend to the more than seventy animals that lived there.

The Farm's structure and location countered the reductive dualism that separates humans from their environment or 'nature', and puts the urban (human's place) in opposition to nature. This echoes David Harvey's contention of the ideological distinction between rural and urban:

The distinction between built environments of cities and the humanly-modified environments of rural and even remote regions then appears arbitrary except as a particular manifestation of a rather long-standing ideological distinction between the country and the city (Williams, 1973). We ignore the ideological power of that distinction at our peril, however, since it underlies a pervasive anti-urban bias in much ecological rhetoric. (Harvey 1993: 3)

The bio-urban moves ecological performance away from the rural-bias assumption that walking through green fields is somehow more 'ecological' than performance in a city. Sherk articulates the bio-urban concept in The Farm's ethos: 'everything found in the country is implicit in the city. Urban environments today, however, due in part to technological excesses, fragment our spaces and lives so that we have difficulty experiencing whole systems' (Sherk 2012: 165). The Farm was a bio-urban performance work that recognized the aliveness of the living world within the built environment, which can illuminate or activate radical ways of human and more-thanhuman coexistence.

The bio-urban is about mediating and communicating ecological agency within urban environments or the way the city is always already embedded in 'nature'. 'Bio' comes from the Greek root meaning living or life. From an ecomaterialist position the biourban reconceives the city, urban or built environment as alive with ecological 
relationships and vibrancy. The term also implies an interweaving and dynamic relationship between urban living and engagement with the more-than-human world as developed at The Farm. Tending to crops while living in dense urban housing, surrounded by motorways was made compatible for the community members involved. The bio-urban is a revised notion of urbanism, an assemblage of dynamic and vibrant ecological relationships that open up possibilities rather than 'dark' inevitabilities.

The city and the country divide has racial undertones, particularly in the US and the UK. Cultural geographer Carolyn Finney argues that the national sentiment of 'the countryside implicitly excluded black people' (2014: 7). This is opposed to the city in which there are 'ghettos' and the euphemism 'urban' operates as code for Black people and culture. The 'country' and related 'nature' activities, such as hiking, birdwatching and camping, are coded as 'morally pure' and 'white' activities that exclude people of colour, perpetuated by a lack of representation. Consequently, the city is coded as 'dangerous', the place where people of colour live and work in 'ghettos'. These reductive racial stereotypes are a further product of the problematic binary that separates the city from the more-than-human world. One of the ways to reconceptualize the urban/nature divide and anti-urban bias is through the idea of the bio-urban. The Farm attempted to redress this harmful divide, and attendant cultural stereotypes, through making it a place for the local communities.

The area of the The Farm was bordered by four neighbourhoods described by Sherk as 'low-income, high need' (Sherk cited in Galpin 2013): Mission, Bernal Heights, Potrero Hill and Bayview communities. These San Francisco neighbourhoods were home to people of colour, immigrants, lesbian, gay, bisexual, transgender and queer (or questioning) (LGBTQ+) people and counterculture movements such as artists and punks. Sherk envisioned it as an experimental community and agricultural centre. 'In addition to wanting to develop a place where people could experience live animals, I saw this land configuration as a way to bring people from these diverse communities together, as well as plants and animals' (ibid.). Diversity sat at the heart of The Farm, within it 'many people of different ages, backgrounds and colours come and go, participating in and creating a variety of programmes which richly mix with the life processes of plants and animals' (Sherk 2012: 166). Sherk's conception of an 
urban agricultural space included a sense of intersectionality with the social, political, cultural and ecological elements of the area. This can be read as intersectional ecologies, a necessary nuancing of the bio-urban.

Intersectional ecologies are articulated artfully by Rebecca Solnit's (2006) connection of Jane Jacobs's city planning, Rachel Carson's environmentalism and Betty Friedan's feminism, all contemporaries published in the early 1960s. Jacobs influential book, The Death and Life of Great American Cities (1992 [1961]), problematized the then dominant planning paradigms of 'modern' cities, designed on principles of separation, segregation and auto-centrism, which deepened inequalities rather than addressed them. Jacobs posited a city that is accessible and works for everyone, supported by diversity principles of communities and mixed-use spaces. Similarly, Friedan's The Feminine Mystique (1963) was a response to the conditions created by the separation and isolation Jacobs wrote about (the gendered suburban disaffection). Solnit connects these two projects to Carson's Silent Spring (1962), credited as popularizing modern American environmentalism:

$[T]$ he suburbanization Jacobs excoriated was designed to produce the all-tooprivate lives Friedan investigated. Together, these three writers addressed major facets of the great modern project to control the world on every scale, locating it in the widespread attacks on nature, on women and on the chaotic, the diverse, the crowded and the poor. (Solnit 2006)

Revisioning the city in ways that works for all people means acknowledging the ecology of the city and the effects of urbanization, while, at the same time, working towards equality and access for all, questioning the dominant logic of neoliberal capitalism and the modern project of 'control'. These ideas were also among the central aims of The Farm.

Although all three were white North American women, whose work is not without problematic elements (Friedan's omission of the experiences of women of colour and working-class women as only one example), they each addressed marginalization in some form. By bringing these three projects together Solnit is gesturing towards intersectional ecologies where ecological destruction disproportionately affects 
women, the poor, people of colour, disabled people and other marginalized people and is therefore tied to other forms of violence, political power and social mobility. Together these three thinkers suggested a need for revisioning city life as diverse and ecologically vibrant, which works for all communities (including the more-thanhuman) based on principles of access, equality and liberation. This position is crucial to the idea of the bio-urban: ecological issues are innately connected to social and political structures that shape urban life in often unjust ways.

The Farm also provides an example of one of the core positions of the bio-urban: problematizing a reductive idea that cities are not part of 'nature' or that they are less 'ecological' than the suburbs or rural areas. While the development of cities has a major environmental impact, and requires outlying land to support them, cities can also be efficient at distributing resources, as 'per capital environmental impacts, across the board, decrease with increasing density' (Farr 2008: 26). City dwellers can sometimes have a lower ecological footprint than those who live in the country (Farr 2008).[\{note]\}2 Cities can also be home to great biodiversity and ecologically thriving spaces, as The Farm demonstrates. Cities are not inherently less ecological than the country, particularly considering intensive, industrial agricultural practices in rural areas that can be ecologically damaging, including contaminating groundwater and soil with fertilizers and pesticides. The Farm's biodiversity and efficient agricultural practices demonstrate the concept of the bio-urban by breaking down binaries in an acknowledgement that cities are part of a vibrant nature and the ecology of the more-than-human world. Cities are both 'nature' and 'culture'. The Farm hosted local children who would come to interact with animals, tend crops or take a dance class, offering gardening, agriculture, animals and an educational centre to the local communities while also attracting animals, insects and wildlife to the site. Sherk viewed the project as a way to explore the potential of different ways of coexisting in the city, through the integration of the surrounding neighbours, both human and more-than-human (2012: 166).

The Farm enacted an ecomaterialist perspective through its expansion of community and agency of food. Sherk's work considers a human urban dweller, not in opposition to the natural world, but always co-mingling with a multiplicity of species. Her vision was based on the idea of the site being alive with different materials and 
creatures. This ecomaterialist view acknowledges the agency of humans in an interdependent relationship with all the other vibrant matter of the site.

Ecomaterialism aims to challenge binary thinking that supports the perception of the more-than-human world as something inanimate, devoid of agency or meaning and separate from human life. I extend this thinking to the bio-urban to consider the way in which performance can manifest the vibrancy of the material world and ecological agency of the city, moving away from binaries towards intersectional ecological thinking. The Farm did this by conceptualizing the city as alive, full of living processes and relationships, including urban food growing. Jane Bennett (2010:42) refers to food as an 'operator', as it is an assemblage of 'things' and relationships: it creates effects through economics, transportation, pesticides, agribusiness and labour, soil, pollination, ingredients and sustenance, health and much more. This assemblage implicates a number of people, practices and ecologies and can catalyse the public. The Farm's urban agriculture recognized how vital food production is in ecological terms and in this way animated the local public (artists, school children, elderly people) in participating in its production.

As the urban experience is quickly becoming one of the most common, it is imperative that we start to think of the city as ecologically vibrant, so that growth and development may be reframed in ecological terms. Considering the way in which the city has ecological agency may help to understand urban development in social, political and ecological contexts. The Farm imagined other possibilities of resistance, control over nature, community, well-being and connection to 'nature'. It existed outside of the dominant capitalist system (formally as a non-profit public trust), providing a home for artists as well as food and education for the local communities. 'Crossroads Community [the community within The Farm] offered a living model for social change and implementing justice' (Spaid 2012: 111). This was a form of 'dark' cultural resistance, providing ways of conceiving of city life as resistant to the grand narrative of progress, reimagining what urban life could be for humans and morethan-humans. In 1981, The Farm was served with an eviction notice and the site was turned into a conventional park (La Raza Park), although it contains community gardens and artists' studios as a legacy of the project. The dominant, planning paradigm reasserted itself, but for a brief time The Farm was a bio-urban 'fissure in the urban fabric', which 'interrupt[ed] the homogenising and hypnotising effects of 
capitalist standardisation' (Highmore 2002: 140-1) to uncover the ecological vibrancy of the city. By confronting these 'dark' ecological practices The Farm was able to imagine and exercise different ways of living together in the city. The concept of the bio-urban maintains the urban as ecologically vibrant, and blurs the boundaries between rural and urban, giving space for radical coexistence of humans and the more-than-humans in the city based on justice, equality and decommodification.

\section{Mierle Laderman Ukeles's work at the New York Sanitation Department (1976- present)}

Mierle Laderman Ukeles's feminist, intersectional ecological art practice focuses on the materiality of waste in New York City, by making unseen waste management systems visible. She is (the first and only) artist in residence at the New York City Sanitation Department. Her work there has included Touch Sanitation (1979-80) in which she proceeded to shake hands with all 8,500 sanitation workers in the department, saying, 'Thank you for keeping New York City alive.' This action connects the vibrancy or aliveness of the city to the networks of often undervalued people and labour, waste materials and processing, making visible everyday ecological relationships.

Like Sherk her work revisions human/more-than-human relationships and interactions, conceiving of an urban 'community' as made up of multiple materials. Her work also engages with the ethics, politics and often gendered nature of care and maintenance work. She wrote the Manifesto for Maintenance Art 1969! (2013) and began to undertake the seemingly everyday domestic acts of maintenance as her art practice after becoming a parent. The manifesto included ideas for an exhibition on Maintenance Art on Care divided into three parts: the personal care and maintenance work carried out by Ukeles; general maintenance work carried out by people in all kinds of jobs, such as "maintenance "man," maid, sanitation "man," mail "man," union "man," construction worker'; and Earth Maintenance. Although she separates private, general and Earth maintenance into three parts, she considers them all as interconnected forms of maintenance, each undervalued in their own way. The private domestic maintenance work done often by women draws a parallel 
to the general maintenance work often carried out as low-wage and undervalued jobs. Earth maintenance is also undervalued and becomes both a private and general act, at times domestic and mundane while other times done by the labour of undervalued workers (such as sanitation workers).

Ukeles takes the usually unseen labour of maintenance work and recontextualizes it within urban ecological terms. Her piece Flow City (1983-2001) involved plans for a visitor centre in the newly built 59th Street Marine Transfer Station in Manhattan, where waste was unloaded from garbage trucks to barges and transferred to Fresh Kills Landfill on Staten Island via the Hudson River. Ukeles (2012) envisioned the centre as a 'public environment' with the aim of embedding art and public participation in the waste management system. Visitors would enter through a Passage Ramp made of recycled materials including glass and rubber, and then proceed to a Glass Bridge. While the Glass Bridge was built as part of the transfer station that opened in 1996, the rest of Flow City remained imagined due to lack of funding. Ukeles's detailed plans form much of the work. The bridge contained three very different views of the city: to the east was a panoramic view of the city skyline or the 'formal city with the icons of New York'; to the west was the trucks dumping their waste on the barges, passing under the bridge in the 'Violent Theatre of Dumping'; and to the south at the end of the bridge she planned a Media Flow Wall (42-3). The three perspectives of the Glass Bridge 'provided a range of views for visitors to see and question everyday consumer choices and to learn more about the consequences of their lifestyle on creating a healthy environment in the future' (Krug 2006). These perspectives drew the attention of residents to the scale of the waste they produce and the labour it takes to process it, making visible what it takes to 'keep the city alive'.

The Media Flow Wall was envisioned to have twenty-four monitors encased in a crushed glass wall with video displays from scientists, ecologists, artists and local experts providing context on urban ecological issues and waste management. It would also include live footage from six cameras of the Hudson River outside and under the station (including under water). As the site restricted access to the river, Ukeles wanted the presence of the river in the centre, as 'this river makes the city live' (Ukeles 2012: 43). The wall would also contain documentation of the garbage 
accumulating at Fresh Kills Landfill. She envisioned the wall as allowing visitors to pass "through" this physical point in order to get a broader understanding of how this kind of place links up with the systems of the planet' (ibid.). The unseen and often forgotten general maintenance work of garbage collection is paired with the images of where the garbage ends up, the Earth maintenance, creating visual links between these ecological relationships.

Ukeles's work demonstrates an important aspect of the bio-urban. In order to dissolve the dichotomy between the urban and so-called nature, we must acknowledge that the ecological is not always (and perhaps not usually) verdant green spaces. Waste and garbage are as much a part of urban ecology as city parks and farms. Replacing 'green' with these 'darker' shades can help us understand our ecological relationships beyond superficial levels. The whole of a city is part of the more-than-human world and embedded in ecological relationships (that also have ethical, social, political and community dimensions). The social and political dimensions of ecology can be hidden or invisible when our image of 'nature' is limited to rolling green hills or anything 'green'. Urban areas are where many of these social-political-ecological relationships play out in our everyday lives. As landscape architect Michael Hough (2004) suggests, an underground system of public transportation is an ecological system, and when we start to think of it as such, we may start to recognize its vibrancy and design and utilize it as such. Ukeles's work contextualizing the waste management system as an ecological system, facilitated by people, sanitation workers as well as more-than-human actants, helps to understand it as an ecological system that we are a part of, including the 'dark' consequences of our behaviour. Ukeles's work asks us to imagine what maintenance and care might be like if we valued it (outside of capitalist terms) and understood it as part of living ecologies that we are always already participating in.

Waste transfer stations are contentious topics in New York City as diesel trucks pollute the air, causing high rates of asthma, and the workers at the sites are often undertaking dangerous work on a low-wage without unionization (Sze 2007: 11011). In 2001, NYC closed Fresh Kills Landfill (the largest landfill in the world), which was the last municipally operated landfill in the city. Privatization of residential waste 
management meant more use of waste transfer stations located within the city. Garbage and waste management 'is an urban and racial matter, with political, economic, and geographical implications... The neighbourhoods particularly vulnerable to changing garbage policies are poor and working-class neighbourhoods' (113). There is a higher proportion of putrescible waste transfer sites in low-income neighbourhoods with more than half of them located in the South Bronx and Williamsburg/Greenpoint, with these sites handling 73 per cent of the cities waste (114). Environmental justice activists in these neighbourhoods (with high populations of people of colour) have organized to ask 'important questions about the distribution of benefits and burdens of city services and how the allocation of these burdens and benefits was influenced by race, class, and politics' (116). Garbage is lighting rod for many intersectional ecological issues in cities. David Harvey (1989) configures garbage as both metaphor for disposable and fictitious capital and material in the unevenly distributed waste management system. Garbage represents the global flow of capital and alienation with an emphasis on instantaneity and disposability.

Workers are alienated from the products of their labour, many (affluent) residents are alienated from the consequences of their lifestyles and users of these objects are alienated from their disposal. 'In 2000, New York City residents and businesses generated approximately 43,000 to 45,000 tons of waste per day' (Sze 2007: 112). Trash has replaced manufacturing and production as an export of NYC, as waste paper is now the biggest export (Sze 2007). In Ukeles's work, these issues were embedded in Fresh Kills Landfill, as 'this fraught and fragile ecosystem represents what it means to dwell within the messy vitality, remarkable diversity, and extraordinary complexity of the world' (Phillips 2016: 27). Ukeles's work aimed to connect people to invisible urban ecological relationships, recognizing the way rubbish can never be thrown 'away', as it continues to exercise agency. Focused on the affectiveness of waste and the feminist issue of maintenance work, Ukeles's performance art highlights the inseparability and intersectionality of waste, ecology, labour and social structures in an urban context.

\section{Towards radical coexistence in the city}

The pervasiveness of the nature/culture (and therefore human/nature and urban/nature) dichotomy has proven difficult to overcome, within scholarship and 
how we interact and think about our relationship to the more-than-human world more generally, as both nature and culture have been deeply contested terms with multiple definitions across history (Cless 2010: 2). The work of Sherk and Ukeles demonstrates how performance can dissolve this reductive dualism by shifting how we see human and more-than-human relationships, towards the 'bio-urban' in an effort to convey a sense of the life and vibrancy of the ecological world, from an ecomaterialist position. These works revision and present the city as an assemblage of ecologically vibrant materials, breaking down binaries and acknowledging dynamic human-nature-social-political ecosystems. Although the sites of these works are in global American cities, the participation of under-represented humans and morethan-humans open them up to intersectional ecological readings. We may be living in 'dark' ecological times, but these works represent small revolutions in coexistence, radical examples of the way we can reclaim the city, understanding its ecological vibrancy and 'aliveness', making it more equitable, pleasurable and just.

\section{Notes}

1 Dark is in quotation marks to reference the tension in the term. Dark and its attendant synonyms (that is, black, covert, negative) have been used to reinforce an anti-Black racist ideology that associates 'dark' skin with danger, anger and evil. While nature activities and environmentalism have been coded as 'white' and have excluded Black people (Finney 2014) the aim of dark ecology is to dispel the myth of a pristine and seperate nature, attempting to undo these exclusionary associations. The multiple ways of interpreting the term are gestured to through the use of quotation marks.

2 For example, in America by 'per unit land area, cities generate a great deal of pollution. However, on a per capita basis, city dwellers generate the least $\mathrm{CO} 2$ ' (Farr 2008: 25-6). These figures are specific to different countries and their infrastructure.

\section{References}

Bennett, Jane. (2010) Vibrant Matter: A political ecology of things, Durham, NC: Duke University Press. 
Buell, Lawrence. (2013) 'Foreword', in Jeffrey Jerome Cohen (ed.) Prismatic Ecology: Ecotheory beyond green, Minneapolis, MN: University of Minnesota Press, pp. ix-xii.

Carson, Rachel. (1962) Silent Spring, Boston, MA: Houghton Mifflin.

Cless, Downing. (2010) Ecology and Environment in European Drama, New York, NY: Routledge.

Farr, Douglas. (2008) Sustainable Urbanism: Urban design with nature, Hoboken, NJ: Wiley.

Finney, Carolyn. (2014) Black Faces, White Spaces: Reimagining the relationship of African Americans to the great outdoors, Chapel Hill, NC: The University of North Carolina Press.

Friedan, Betty. (1963) The Feminine Mystique, London: Victor Gollancz.

Galpin, Pierre-François. (2013) 'Cultivating the human \& ecological garden: A conversation with Bonnie Ora Sherk', http://curatorsintl.org/posts/cultivating-thehuman-ecological-garden-a-conversation-with-bonnie-ora-sher, accessed 9 February 2016.

Gaston, Kevin. J. (ed.) (2010) Urban Ecology, Cambridge and New York, NY: Cambridge University Press.

Harvey, David. (1989) The Condition of Postmodernity: An enquiry into the origins of cultural change, Cambridge and Oxford: Blackwell.

Harvey, David. (1993) 'The nature of environment: Dialectics of social and environmental change', in R. Miliband and L. Panitch (eds) Real Problems, False Solutions, London: Merlin Press, pp. 1-51. 
Highmore, Ben. (2002) Everyday Life and Cultural Theory: An introduction, London and New York, NY: Routledge.

Hough, Michael. (2004) Cities and Natural Process: A basis for sustainability, 2nd edn, London and New York, NY: Routledge.

Jacobs, Jane. (1992 [1961]) The Death and Life of Great American Cities, London: Vintage.

Krug, Don. (2006) 'Ecological restoration: Mierle Ukeles, Flow City', www.greenmuseum.org/c/aen/lssues/ukeles.php, accessed 9 February 2016.

Morton, Timothy. (2016) Dark Ecology: For a logic of future coexistence, New York, NY: Columbia University Press.

Nixon, Robert. (2011) Slow Violence and the Environmentalism of the Poor, Cambridge, MA: Harvard University Press.

Phillips, Patricia C. (2016) Mierle Laderman Ukeles: Maintenance art, Flushing Meadows-Corona Park, Queens, New York, NY and Munich and New York, NY: Prestel.

Sherk, Bonnie. (2012) 'Crossroad Community: The Farm // 1977', in Jeffrey. Kastner (ed.) Nature, London: Whitechapel Art Gallery and Cambridge, MA: MIT Press, pp. 165-6.

Solnit, Rebecca. (2006) 'Three who made a revolution', The Nation. www.thenation.com/article/three-who-made-revolution/, April 3, 2006, accessed 7 July 2019.

Spaid, Sue. (2012) Green Acres: Artists farming fields, greenhouses and abandoned lots, Cincinnati, $\mathrm{OH}$ : Contemporary Arts Center.

Sze, Julie. (2007) Noxious New York: The racial politics of urban health and 
environmental justice, Cambridge, MA and London: MIT Press.

The Dark Mountain Project (2015) 'About', The Dark Mountain Project, http://darkmountain.net/about/the-dark-mountain-project/, accessed 4 September 2015.

Ukeles, Laderman Mierle. (1996) ‘Flow City’, Grand Street 57: 199.

Ukeles, Laderman Mierle. (2012) 'Flow City (1983-91) // 1995', in Jeffrey Kastner (ed.) Nature, London: Whitechapel Art Gallery and Cambridge, MA: MIT Press, pp. 42-3.

Ukeles, Laderman Mierle. (2013) Manifesto for Maintenance Art, 1969-Arnolfini, www.arnolfini.org.uk/blog/manifesto-for-maintenance-art-1969, accessed 2 August 2018. 